\title{
Development of Nanozyme-Labeled Biomimetic Immunoassay for Determination of Sulfadiazine Residue in Foods
}

\author{
Jingbo He, ${ }^{1}$ Li Zhang, ${ }^{1}$ Longhua $\mathrm{Xu}^{1}{ }^{1}$ Feifan Kong, ${ }^{2}$ and Zhixiang $\mathrm{Xu} \mathbb{C}^{1}$ \\ ${ }^{1}$ Key Laboratory of Food Processing Technology and Quality Control in Shandong Province, College of Food Science and Engineering, \\ Shandong Agricultural University, Taian 271018, China \\ ${ }^{2}$ Shandong Wuzhou Testing Co., Ltd., Sishui 273200, China
}

Correspondence should be addressed to Zhixiang Xu; zhixiangxu@sina.com

Received 16 March 2020; Accepted 18 April 2020; Published 12 May 2020

Academic Editor: Gyorgy Szekely

Copyright (c) 2020 Jingbo He et al. This is an open access article distributed under the Creative Commons Attribution License, which permits unrestricted use, distribution, and reproduction in any medium, provided the original work is properly cited.

The excessive use and ingestion of residues of sulfonamides harm the human body and the environment. To meet the requirements of the maximum residue limit specified by the Ministry of Agriculture of China, a rapid detection method urgently needs to be developed. In the present study, a molecularly imprinted polymer (MIP) that could selectively recognize sulfadiazine (SDZ) was prepared using SDZ as the template molecule and methacrylic acid as the functional monomer. Using MIP as biomimetic antibody and $\mathrm{Au@Pt@SiO}{ }_{2}$ nanozyme as a marker, a new biomimetic immunoassay was developed to detect sulfadiazine. Under the optimal conditions, the limit of detection $\left(\mathrm{IC}_{15}\right)$ and sensitivity $\left(\mathrm{IC}_{50}\right)$ of this method were 0.09 and $6.1 \mathrm{mg} / \mathrm{L}$, respectively. To determine the accuracy of this method, honey and milk samples spiked with sulfadiazine were analyzed, with recoveries in the range of $70.8 \%-90.2 \%$. The method was also used for the quantitative analysis of sulfadiazine residues in milk powder and milk samples, producing results which correlated well with those obtained by high-performance liquid chromatography.

\section{Introduction}

Sulfonamides are a common type of broad-spectrum antibiotic, which are widely used in livestock and poultry breeding because they are effective and low cost [1]. However, the improper and excessive use of these drugs can lead to residues in foods and the environment, thus causing potential harm to human health through the food chain $[2,3]$. Therefore, the residues of sulfanilamide drugs have aroused great attention in research studies. To ensure the safety of food for consumers, the Ministry of Agriculture of China has stipulated that the maximum residue of sulfonamides in animal food should be $0.1 \mathrm{mg} / \mathrm{kg}$ [4]. To meet this requirement, developing methods for monitoring and the rapid detection of sulfanilamide residue is of great importance.

Many detection methods for pesticide and veterinary drug residues have been established. Among them, microbial bacteriostatic methods lack sensitivity, specificity, and require tedious preparation, so their application has been less popular [5]. Other reported methods include spectrophotometry [6], enzyme-linked immunoassay [7], chromatogra- phy, and mass spectrometry [8]. Of these methods, highperformance liquid chromatography (HPLC) has become the most widely used detection method because of its advantages of good selectivity, high sensitivity, and reproducibility [9-11]. However, this method requires expensive equipment, has complicated operational procedures, and is timeconsuming. Enzyme-linked immunoassay is one of the usual technologies for detecting small molecule drug residues, which takes advantage of the immune response between antigens and antibodies, and the ability of enzymes to catalyze the reaction $[12,13]$. Therefore, this operation is sensitive, and specificity is good [14]. However, the low stability of the biological antibody limits its application in immunoassays. To overcome this problem, many studies have focused on developing bionic antibodies. Molecularly imprinted polymer (MIP) has many complementary cavities to the template molecule in shape, size, and chemical function, making them specific and selective to the target molecule [15-17]. During the past decades, the increasing trend of imprinting biologically active compounds ranging from small pharmaceutical molecules to large biomacromolecules including 
myoglobin, naproxen, antioxidants, diclofenac and urea has been numerously reported [18-22]. The synthesized polymer has the advantages of high stability [23], specific recognition, and low cost and has proved to be an ideal biomimetic antibody to replace biological antibodies [24, 25]. More recently, many biomimetic enzyme-linked immunosorbent assay (BELISA) methods have been reported [26, 27]. However, most of these methods use natural enzymes as markers; despite their high catalytic activity, their complex structures and low stability could affect the analytical results [28]. Therefore, a new marker is needed to replace natural enzymes.

Nanozyme is a type of artificial nanoparticle (NP) $[29,30]$. With the characteristics of adjustable enzyme-like catalytic activity, simple preparation, and high stability, it has been applied for detecting small molecules [31-33]. For example, platinum nanoparticles (Pt NPs) often exhibit high catalytic activity, especially when hybridized with other metals, so they have gained extensive attention for electrochemical catalysis [34] and catalytic hydrogenation [35]. In comparison with $\mathrm{Pt}$ alone, bimetallic nanostructures can not only enhance the catalytic activity but also improve the stability of NPs. Pt also exhibits a good growth mode on gold surfaces [36], and the Au@Pt bimetallic materials can reduce the aggregation of Pt NPs and increase their catalytic activity [37-40]. $\mathrm{SiO}_{2}$ NPs are ideal carriers when combined with other metal NPs [41, 42]. To improve the efficiency antigen connection, Au-Pt NPs were surface modified with mesoporous silica in the present study. Using the MIP as the biomimetic antibody and the Au@Pt@SiO ${ }_{2}$ nanozyme as a label, a novel and sensitive BELISA method for determining SDZ residues will be established. The factors influencing the sensitivity of analytical method will be optimized in detail, and the peroxidase activity and stability of the nanostructures will be evaluated.

\section{Experimental}

2.1. Materials. Milk (including a and b samples), milk power, and honey samples were obtained from a supermarket (Taian, Shandong, China) in November 2019.

2.2. Reagents and Chemicals. The sulfadiazine ( $>98 \%$ purity) was purchased from the Shandong Xiya Chemical Industry Co., Ltd. (Linyi, China), sodium borohydride $\left(\mathrm{NaBH}_{4}, \mathrm{AR}\right)$ from Tianjin Kemiou Chemical Reagent Co., Ltd. (Tianjin, China), cetyltrimethylammonium bromide (CTAB, AR), $3,3^{\prime}, 5,5^{\prime}$-tetramethylbenzidine (TMB, 99\% purity) and chloroauric acid $\left(\mathrm{HAuCl}_{4} \cdot 3 \mathrm{H}_{2} \mathrm{O}, \mathrm{AR}\right)$ from Beijing Biotopped Science \& Technology Co., Ltd. (Beijing, China), tetraethoxysilicane (TEOS, $>99 \%$ purity) from Shanghai Macklin Biochemical Co., Ltd. (Shanghai, China), 3-aminopropyl triethoxysilane (APTES, >99\% purity) from Shanghai Yuanye Bio-Technology Co., Ltd. (Shanghai, China), methacrylic acid (MAA, >99\% purity), 2,2-azobisisobutyronitrile (AIBN, $>99 \%$ purity), ethylene glycol dimethacrylate (EGDMA, $>99 \%$ purity), methanol (AR), acetic acid (AR), and acetonitrile (AR) from Tianjin Chemical Reagent Factory (Tianjin, China), silver nitrate $\left(\mathrm{AgNO}_{3},>99 \%\right.$ purity) and L-ascorbic acid (AR) from Tianjin Kaitong Chemical Reagent Co. Ltd.
(Tianjin, China), and dimethyl sulfoxide (DMSO, 99\% purity) from Shanghai Aladdin Biochemical Technology Co., Ltd. (Shanghai, China).

2.3. Apparatus. The UV spectra were recorded using a UV-5500 spectrophotometer (Shanghai Metash Instruments Co. Ltd., Shanghai, China). The characteristic UV absorption peaks of the nanozyme were determined by a UV-2450 fullwavelength scanner (Shanghai Metash Instruments Co. $\mathrm{Ltd})$. The FT-IR spectra in $\mathrm{KBr}$ were obtained using a NICOLET iS10 spectrometer (Thermo Fisher Scientific, Waltham, MA, USA). High-performance liquid chromatography (HPLC) was used to detect the sulfadiazine residues in milk, honey, and milk powder (Shimadzu Corp., Kyoto, Japan), with a Kromasil 100-5-C18 chromatographic column $(250 \times 4.6 \mathrm{~mm}, 5 \mu \mathrm{m})$ (Nouryon Separation Products, Bohus, Sweden).

2.4. Synthesis of $A u$ NPs. The Au NPs were synthesized by a seed-mediated method [43]. First, $7.5 \mathrm{~mL}$ of a CTAB $(0.1 \mathrm{M})$ aqueous solution was mixed with $100 \mu \mathrm{L}$ of $\mathrm{HAuCl}_{4}$ $(24 \mathrm{mM})$, and then $1.8 \mathrm{~mL}$ of deionized water was added to dilute the mixture. Then $0.6 \mathrm{~mL}$ of ice-cold $\mathrm{NaBH}_{4}(0.01 \mathrm{M})$ was added quickly. After the solution was stirred magnetically for $3 \mathrm{~min}$, the color of the solution changed from bright yellow to brown, which indicated that the Au seeds had been formed. $240 \mu \mathrm{L}$ of the Au seed was added to the preparation growth solution and incubated at $28^{\circ} \mathrm{C}$ for $12 \mathrm{~h}$, and then the $\mathrm{Au}$ NPs were purified by centrifugation $(10656 \times g$, $10 \mathrm{~min})$ twice. The sediment was then redispersed in double-distilled water.

The growth solution for the Au NPs consisted of $100 \mathrm{~mL}$ CTAB (0.1 mM), $2.04 \mathrm{~mL} \mathrm{HAuCl}_{4}(24 \mathrm{mM}), 2 \mathrm{~mL} \mathrm{H}_{2} \mathrm{SO}_{4}$ $(0.5 \mathrm{M}), 1 \mathrm{~mL} \mathrm{AgNO}_{3}(10 \mathrm{mM})$, and $800 \mu \mathrm{L} \mathrm{L}$-ascorbic acid $(0.1 \mathrm{mM})$.

2.5. Synthesis of Au@Pt NPs. The Au@Pt NPs were synthesized as follows: the Au NPs ( $1 \mathrm{~mL}$ ) were diluted to $2 \mathrm{~mL}$ with deionized water, and then $120 \mu \mathrm{L}$ of $\mathrm{K}_{2} \mathrm{PtCl}_{4}$ solution and $1.2 \mathrm{~mL}$ of L-ascorbic acid were added. After the mixture was mixed vigorously, the solution was reacted at $30^{\circ} \mathrm{C}$ for $30 \mathrm{~min}$. After adding $1 \mathrm{~mL}$ of CTAB to stop the reaction, the mixed solution was purified by centrifugation $(7104 \times g$, $10 \mathrm{~min})$. The resulting precipitate was redissolved in $1 \mathrm{~mL}$ deionized water.

2.6. Synthesis of Au@Pt@SiO ${ }_{2}$ and the Nanozyme Conjugate. The Au@Pt@SiO ${ }_{2}$ NPs were prepared as follows: Ten milliliters of the Au@Pt NP solution was centrifuged $(5772 \times g$, $10 \mathrm{~min}$ ), and the precipitate was dispersed in $10 \mathrm{~mL}$ of deionized water. The $\mathrm{pH}$ of the solution was then adjusted to 10.6 using a solution of $\mathrm{NaOH}(0.1 \mathrm{M})$. The mixture was stirred magnetically for $20 \mathrm{~min}$, and then $10 \mu \mathrm{L}$ of TEOS ethanol solution $(20 \% v / v)$ were added 3 times at 30 min intervals. Finally, this mixed solution was reacted at $30^{\circ} \mathrm{C}$ for $24 \mathrm{~h}$. After $20 \mu \mathrm{L}$ of APTES was added, the mixture solution was ultrasonicated for $2 \mathrm{~h}$, before washing twice with ethyl acetate and ethanol.

Five milliliters of Au@Pt@SiO 2 NPs and $10 \mu \mathrm{L}$ of glutaraldehyde were added to a reaction vessel. After stirring 
magnetically for $1 \mathrm{~h}$, an equimolar mass of SDZ solution was added, and then the solution was stirred for another $1 \mathrm{~h}$. Finally, these products were washed with methanol to remove unreacted materials and preserved at $4^{\circ} \mathrm{C}$.

2.7. Preparation of the SDZ MIP. The procedure for synthesizing the MIP was as follows: $0.25 \mathrm{~g}(1 \mathrm{mmol})$ of sulfadiazine and $0.35 \mathrm{~g}$ of MAA ( $4 \mathrm{mmol})$ were dissolved in $11 \mathrm{~mL}$ of acetonitrile, and then $4 \mathrm{~mL}$ of DMSO was added. The mixture was stirred at room temperature for $30 \mathrm{~min}$, and then $3.77 \mathrm{~mL}$ of EGDMA $(20 \mathrm{mmol})$ and $0.02 \mathrm{~g}$ of AIBN were added. The mixture was ultrasonicated for $15 \mathrm{~min}$, blown with nitrogen for $5 \mathrm{~min}$, and then reacted at $60^{\circ} \mathrm{C}$ for $18 \mathrm{~h}$. When the polymerization process ended, the rigid polymer was crushed and sieved with a 200-mesh sieve. The MIP $(20 \mathrm{~g})$ was Soxhlet extracted with $300 \mathrm{~mL}$ of a methanol/glacial acetic acid mixture $(9 / 1, v / v)$ for $24 \mathrm{~h}$ and then washed with $200 \mathrm{~mL}$ methanol for $12 \mathrm{~h}$. Finally, the MIP was vacuum-dried at $60^{\circ} \mathrm{C}$ for $12 \mathrm{~h}$.

For comparison, a nonimprinted polymer (NIP) was prepared using the same experimental process, but no sulfadiazine was added.

2.8. Direct Competitive BELISA Procedure. The procedure for BELISA was as follows: $5 \mathrm{~mL}$ of nanozyme-labeled sulfadiazine antigen and $5 \mathrm{~mL}$ standard solution $(0.0512-32 \mathrm{mg} / \mathrm{L})$ or $5 \mathrm{~mL}$ of sample extract were added to a volumetric flask, and then $5 \mathrm{mg}$ of MIP was added. After shaking for $90 \mathrm{~min}$ and centrifugation $(7104 \times g)$ for $10 \mathrm{~min}$, the absorbance of the supernatant was measured at $270 \mathrm{~nm}$. Separate inhibition rates were calculated.

2.9. Sample Preparation. To determine the feasibility of the BELISA method, milk and honey samples spiked with sulfadiazine were assessed, with the level of sulfadiazine residues determined by HPLC. First of all, $5.0 \mathrm{~g}$ of milk (sample a) and honey samples were accurately weighed into a $50 \mathrm{~mL}$ round-bottom flask and then spiked with $1.0 \mathrm{~mL}$ of a sulfadiazine standard solution $(0.50,2.50$, and $12.50 \mathrm{mg} / \mathrm{L})$. After incubation at $4^{\circ} \mathrm{C}$ for $24 \mathrm{~h}$, the mixtures were extracted twice using $20 \mathrm{~mL}$ of ethyl acetate. The extracts were collected, and the solvent was removed from a rotary evaporator. The extract was then redissolved in $1 \mathrm{~mL}$ of methanol. The resulting extract was analyzed by the BELISA procedure after filtering with a $0.22 \mu \mathrm{m}$ membrane.

To detect the sulfadiazine residue level, milk (sample b) and milk powder samples were prepared as described above, without adding any sulfadiazine standard. The extract was detected by the BELISA and HPLC (GB 29694-2013) methods, and the content of sulfadiazine was calculated.

\section{Results and Discussion}

3.1. Characterization of Au@Pt Nanostructures. The absorption spectra of the Au NPs and Au@Pt nanostructures were assessed using UV-vis-NIR (Figure S1). The Au NPs had an absorption peak at $810 \mathrm{~nm}$, which indicated that they had been synthesized successfully [37]. The Au NPs were coated with Pt to form core-shell Au@Pt nanostructures. After coating with Pt NPs, the band was red-shifted to $835 \mathrm{~nm}$, which indicated that Au NPs@Pt nanostructures had been formed.

3.2. Optimization the Conditions for MIP Synthesis. The proportions between template molecules of SDZ, functional monomers of MAA, and cross-linkers of EGDMA used for the preparation of the MIP were optimized to ensure that the prepared polymer exhibited a high adsorption capacity. The various ratios and adsorption capacities investigated are shown in Table S1. The polymer exhibited a maximum adsorption capacity $(41.09 \mathrm{mg} / \mathrm{g})$ at a ratio of SDZ:MAA:EGDMA of $1: 4: 20$. So this ratio was used throughout the experiments.

3.3. Characterization of MIP. The FT-IR spectra of the imprinted film after extraction (a), the imprinted film before extraction (b), the nonimprinted film (c), and sulfadiazine (d) are compared. Figure S2 shows the sulfadiazine stretching peak near $3475 \mathrm{~cm}^{-1}$ and $3405 \mathrm{~cm}^{-1}$, indicating an $\mathrm{N}-\mathrm{H}$ stretching vibration, with the peak near $1195 \mathrm{~cm}^{-1}$ being assigned to the $\mathrm{S}=\mathrm{O}$ group. For the MIP film before extraction, the features around $1190 \mathrm{~cm}^{-1}$ were identified as $\mathrm{S}=\mathrm{O}$ stretching vibrations. The stretch shift $(\mathrm{S}=\mathrm{O})$ might have resulted from the oxygen atoms of the $\mathrm{S}=\mathrm{O}$ group in sulfadiazine combining with the hydrogen atoms of $-\mathrm{OH}$ in MAA to form hydrogen bonds. However, the $\mathrm{S}=\mathrm{O}$ stretching vibration peak was not found in the imprinted film after extraction, which indicated that the sulfadiazine had been extracted completely. These results demonstrated that the MIP film had been prepared successfully.

A thermogravimetric analysis (TGA) curve of the imprinted film is shown in Figure S3. At a temperature between 0 and $370^{\circ} \mathrm{C}$, there was no significant reduction in the mass of the MIP film. When the temperature exceeded $370^{\circ} \mathrm{C}$, the mass decreased sharply. This showed that the imprinted film had good thermal stability.

To measure the adsorption ability of the imprinted material, $20 \mathrm{mg}$ of MIP and NIP was added to $10 \mathrm{~mL}$ of sulfadiazine standard solution $(100-500 \mathrm{mg} / \mathrm{L})$. The mixture was shaken for $4 \mathrm{~h}$ at room temperature and then centrifuged at $7104 \times g$ for $10 \mathrm{~min}$. The adsorption capacity $(Q)$ of the MIP and NIP was calculated as follows:

$$
Q=\left(C_{0}-C_{1}\right) V / M
$$

where $C_{0}$ and $C_{1}$ are the concentrations of sulfadiazine in solution before and after adsorption, respectively, $V$ is the volume of the solution, and $M$ is the mass of the MIP or NIP.

The adsorption capacity of the MIP and NIP to SDZ increased as the SDZ concentration increased, but the adsorption capacity of the MIP to SDZ was significantly better than that of the NIP (Figure 1). For the same initial concentration of SDZ, the adsorption capacity of the MIP to SDZ was approximately 1.6 times that of NIP, indicating that MIP could adsorb SDZ specifically and had a higher adsorption capacity for SDZ.

The uptake kinetics of the MIP (20 mg) were also investigated by shaking in the SDZ standard solution of $300 \mathrm{mg} / \mathrm{L}$ for $5,30,60,90,120,180$, and $240 \mathrm{~min}$, respectively 


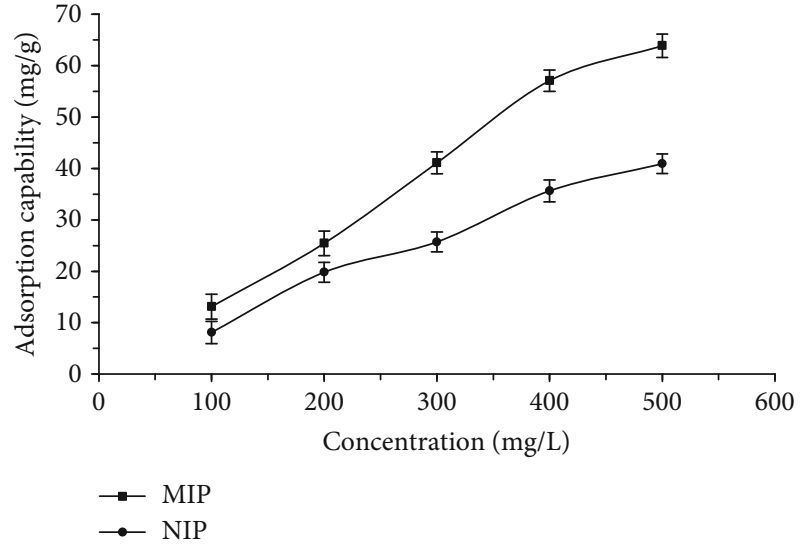

FIGURE 1: Adsorption isotherms of the imprinted and nonimprinted polymers.

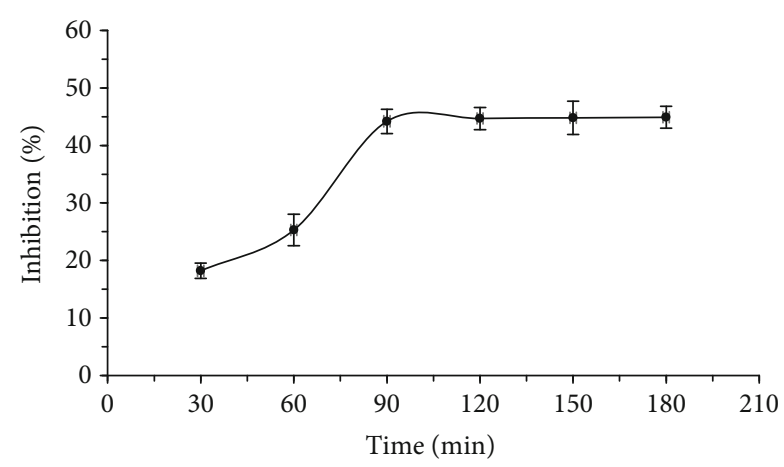

FIGURE 2: The influence of the competitive reaction time on sulfadiazine inhibition.

(Figure S4). After shaking for $60 \mathrm{~min}$, high absorption capacity of $30.53 \mathrm{mg} / \mathrm{g}$ for the MIP was obtained, which was $74.45 \%$ of the maximum adsorption capacity. The adsorption almost approached equilibrium within $120 \mathrm{~min}$. The fast adsorption kinetics of the MIP can meet the need of rapid detection in the BELISA method.

3.4. Optimizing of the BELISA Method. The sensitivity of the BELISA method could be improved by optimizing the reaction conditions: the competition reaction time and the preparation solution in detail. The competition reaction time can influence the binding capacity between the antigen and antibody. In the present study, different antigen-antibody competition binding times of $0,60,90,120,150$, and 180 min were investigated, and then the inhibition rate based on the absorbance value was calculated. Figure 2 shows that the inhibition rate increased with increasing reaction time. At a competitive reaction time of $90 \mathrm{~min}$, the inhibition rate of sulfadiazine reached the maximum. When it was increased from 90 to $180 \mathrm{~min}$, the inhibition rate did not change, indicating that the adsorption had achieved equilibrium. Therefore, the competitive response time was chosen as $90 \mathrm{~min}$.

The recognition capability and selectivity of the MIP towards sulfadiazine were greatly influenced by the preparation solution, thus influencing the accuracy of the BELISA procedure. The use of methanol, acetonitrile, and borate

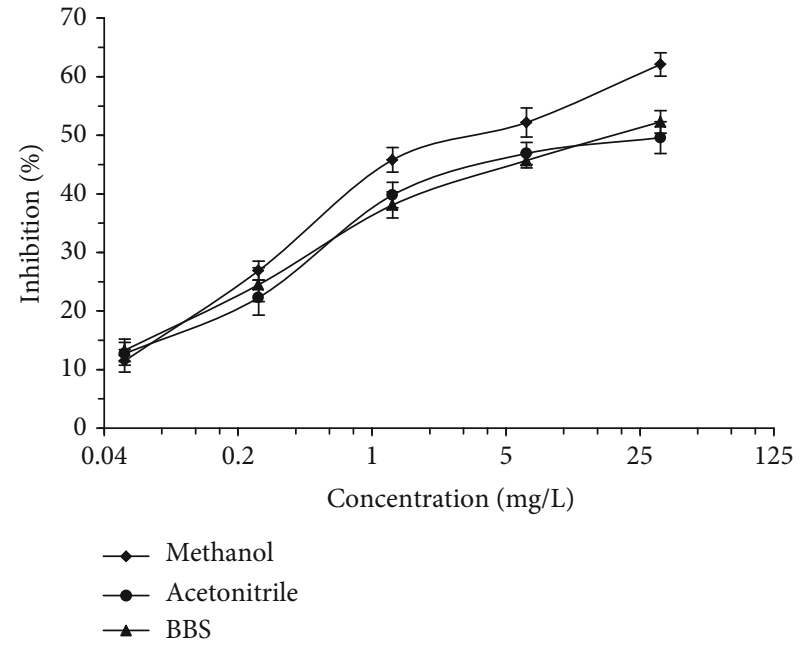

Figure 3: Effect of preparation solutions on the BELISA method.

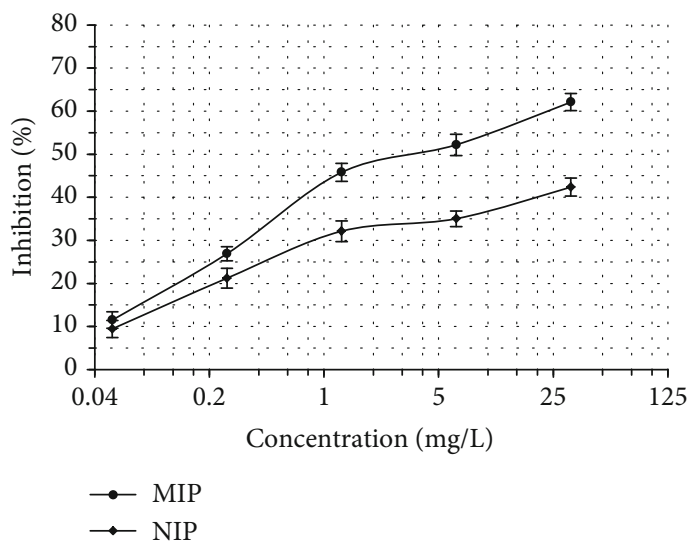

FIgURE 4: Standard BELISA competition curves for sulfadiazine at concentrations from 0.0512 to $160 \mathrm{mg} / \mathrm{L}$ in methanol.

buffer saline (BBS) was studied as preparation solutions. Figure 3 shows that when methanol was used, the inhibition ratio and sensitivity of the method were better than those achieved with the other solutions. Therefore, methanol was used throughout the experiment as the preparation solution.

3.5. Parameters of the BELISA Method. The parameters of the BELISA method for detecting sulfadiazine were evaluated under the optimal conditions. Figure 4 shows that the limit of detection (LOD, $\mathrm{IC}_{15}$ ) and sensitivity $\left(\mathrm{IC}_{50}\right.$ ) of this method were $0.09 \mathrm{mg} / \mathrm{L}(0.02 \mathrm{mg} / \mathrm{kg})$ and $6.1 \mathrm{mg} / \mathrm{L}$, respectively. The Ministry of Agriculture of China has stipulated that the maximum residue of sulfonamides in animal food is $0.1 \mathrm{mg} / \mathrm{kg}$ [4]. Therefore, the LOD of the BELISA method was sufficiently low for it to suitable for determining SDZ residues in food.

3.6. Selective Evaluation of the BELISA Method. To evaluate the selective recognition ability of this method, the MIP and NIP were used as biomimetic antibodies, and the standard curves of BELISA were established under the best experimental conditions (Figure 4). For the same concentration of 
TABLE 1: The structure, sensitivity $\left(\mathrm{IC}_{50}\right)$, and cross-reactivity $(\mathrm{CR})$ ratio of three kinds of antibiotic.

Antibiotics

Values are mean $\pm \operatorname{SD}(n=3)$.

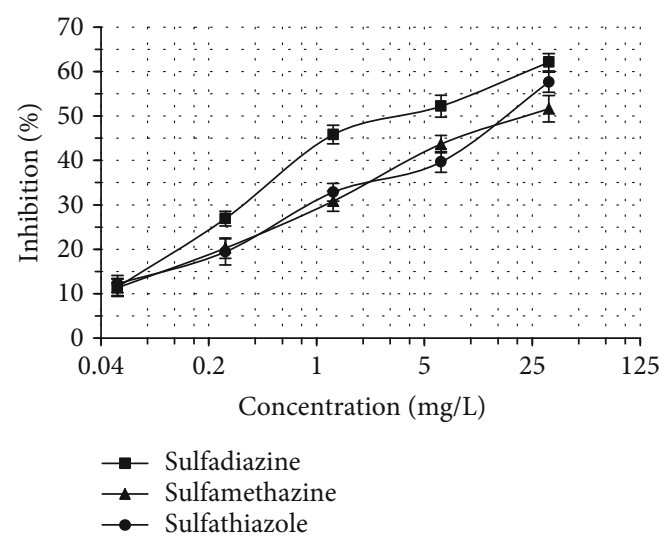

FIGURE 5: Cross-reactivity of three types of antibiotic.

SDZ, the MIP exhibited a significantly higher inhibition rate than the NIP. At a SDZ concentration of $32 \mathrm{mg} / \mathrm{L}$, the inhibition rate for the MIP was $63.48 \%$, while that for the NIP was only $45.36 \%$. Therefore, the MIP had a strongly selective adsorption capacity for sulfadiazine.

The specificity of the new BELISA method was also evaluated by a cross-reactivity experiment with two structural analogs of sulfadiazine (sulfamethazine and sulfathiazole). Results in Table 1 and Figure 5 show that the competition effect of sulfadiazine was more obvious than that of the structural analogs. The cross-reactivity of the biomimetic antibodies with sulfamethazine and sulfathiazole was $16.1 \%$ and $20.3 \%$, respectively. These results confirmed that the MIP had a better recognition ability for sulfadiazine and played a crucial part in competitive immunoassay.

3.7. Accuracy of the BELISA Method. The accuracy of this method was evaluated. The honey and milk (a) samples spiked with SDZ at different levels $(0.5,2.5$, and $12.5 \mathrm{mg} / \mathrm{L})$ were assessed using the BELISA procedure. The results are shown in Table 2 with good recoveries of $71.80 \%-90.20 \%$ being achieved.

To evaluate the applicability of the method, the milk powder and milk (b) samples were analyzed by HPLC and this newly developed method. The SDZ in the milk powder and milk (b) samples were set at levels of $0.30 \pm 0.05 \mu \mathrm{g} / \mathrm{mL}$ and $0.49 \pm 0.06 \mu \mathrm{g} / \mathrm{mL}$, respectively, as assessed through HPLC (Figure S4). The corresponding concentrations obtained by the BELISA method of $0.26 \pm 0.04 \mu \mathrm{g} / \mathrm{mL}$ and $0.46 \pm 0.02 \mu \mathrm{g} / \mathrm{mL}$, respectively, were not significantly different from those obtained by HPLC $(P>0.05)$. These results confirmed that the BELISA techniques has a sufficient accuracy for detecting sulfadiazine in foods.

3.8. Advantages and Disadvantages of the Developed Method. Compared with previously reported methods, this method has many advantages. When using Au@Pt@SiO 2 nanozyme as a marker, the structure of the nanozyme was smaller than that of natural enzymes, so the influence of conjugation can be reduced. Using the MIP as a biomimetic antibody provided a better stability than the biological antibody and could also be reused more than 10 times without the loss of sensitivity. Thus, the stability of the BELISA method was improved and the cost of analysis reduced. The BELISA method has been shown to exhibit excellent sensitivity and applicability, which means it can be used for detecting and analyzing sulfadiazine. However, the catalytic efficiency of nanozyme is currently inferior to natural enzyme. Furthermore, the recognition ability of the molecularly imprinted polymer is clearly lower than of the biology antibody. The BELISA method remains to be improved in further studies.

\section{Conclusions}

In the present study, we have developed a new BELISA method by using a synthetic enzyme in place of a natural 
TABLE 2: The recoveries of spiked sulfadiazine in honey and milk (a) samples determined using the BELISA method.

\begin{tabular}{lcccc}
\hline Samples & Original concentration $(\mathrm{mg} / \mathrm{L})$ & Spiked level $(\mathrm{mg} / \mathrm{L})$ & Analysis result $(\mathrm{mg} / \mathrm{L}, \pm \mathrm{SD})$ & Recovery $(\%, \pm \mathrm{RSD})$ \\
\hline \multirow{3}{*}{ Honey } & \multirow{2}{*}{0.005} & 0.5 & $0.45 \pm 0.01$ & $90.20 \pm 2.20$ \\
& & 2.5 & $2.15 \pm 0.05$ & $85.72 \pm 2.20$ \\
\hline & 12 & $10.76 \pm 0.40$ & $89.63 \pm 3.74$ \\
Milk (a) & \multirow{2}{*}{0.24} & 0.5 & $0.60 \pm 0.02$ & $71.80 \pm 3.51$ \\
& & 2.5 & $2.43 \pm 0.13$ & $87.60 \pm 5.36$ \\
\end{tabular}

Values are mean $\pm \mathrm{SD}(n=3)$.

enzyme as a label. Under the optimal conditions, the limit of detection $\left(\mathrm{IC}_{15}\right)$ and sensitivity $\left(\mathrm{IC}_{50}\right)$ of this method were 0.09 and $6.1 \mathrm{mg} / \mathrm{L}$, respectively. This method was applied to detect sulfadiazine residues successfully and provided good accuracy. The proposed method has potential applications for analyzing antibiotic residues in agricultural and food products, although its sensitivity is lower. With the development of molecular imprinting technology, the sensitivity and accuracy of MIP-based immunoassays would be improved, and they can provide an important analysis platform for analyzing antibiotic residues in agricultural and food products in the future.

\section{Data Availability}

The data has been shown in the Results and Discussion section.

\section{Conflicts of Interest}

The authors declare that they have no conflicts of interest.

\section{Acknowledgments}

This work was financially supported by the Key R\&D Project of Shandong Province (No. 2019GNC106030) and Key R\&D Project of Jining (2019NYNS002).

\section{Supplementary Materials}

Table S1: the effect of the ratio of the components used for synthesizing a MIP on its adsorption. Figure S1: ultraviolet absorption spectrum of Au@Pt nanostructures. Figure S2: FT-IR spectra of the imprinted film (a) before and (b) after extraction and of the (c) nonimprinted film and (d) sulfadiazine. Figure S3: TGA curve of the MIP upon heating from 20 to $600^{\circ} \mathrm{C}$. Figure S4: kinetic uptake plot of the MIP. Figure S5: high-performance liquid chromatograms for SDZ in the milk sample. (Supplementary Materials)

\section{References}

[1] Y. J. Liu, H. T. Bian, B. S. Qu, Y. H. Yong, and Y. M. Zhang, "Research progress on detection of sulfonamides in food," Journal of Food Safety \& Quality, vol. 8, pp. 3420-3430, 2017.

[2] J. S. Chu, Y. Xu, Q. F. He, L. H. Wang, and J. Lu, "Determination of sulfadianzine residues in pork by direct competitive chemiluminescence enzyme immunoassay," Food Science, vol. 32, no. 10, pp. 124-129, 2011.

[3] A. Hiba, A. Carine, A. R. Haifa, L. Ryszard, and J. Farouk, "Monitoring of twenty-two sulfonamides in edible tissues: investigation of new metabolites and their potential toxicity," Food Chemistry, vol. 192, pp. 212-227, 2016.

[4] X. Wang, K. Li, D. Shi et al., "Development of an immunochromatographic lateral-flow test strip for rapid detection of sulfonamides in eggs and chicken muscles," Journal of Agricultural and Food Chemistry, vol. 55, no. 6, pp. 2072-2078, 2007.

[5] Z. Lian, X. He, and J. Wang, "Determination of sulfadiazine in Jiaozhou Bay using molecularly imprinted solid-phase extraction followed by high-performance liquid chromatography with a diode-array detector," Marine Pollution Bulletin, vol. 957, no. 1-2, pp. 53-59, 2014.

[6] E. Kazemi, S. Dadfarnia, A. M. Haji Shabani, M. R. Fattahi, and J. Khodaveisi, "Indirect spectrophotometric determination of sulfadiazine based on localized surface plasmon resonance peak of silver nanoparticles after cloud point extraction," Spectrochimica Acta Part A: Molecular and Biomolecular Spectroscopy, vol. 187, pp. 30-35, 2017.

[7] N. Liu, Z. Han, L. Lu et al., "Development of a new rabbit monoclonal antibody and its based competitive indirect enzyme-linked immunosorbent assay for rapid detection of sulfonamides," Journal of the Science of Food and Agriculture, vol. 93, no. 3, pp. 667-673, 2013.

[8] Y. Lu, B. Cong, Z. Tan, and Y. Yan, "Synchronized separation, concentration and determination of trace sulfadiazine and sulfamethazine in food and environment by using polyoxyethylene lauryl ether-salt aqueous two-phase system coupled to high-performance liquid chromatography," Ecotoxicology and Environmental Safety, vol. 133, pp. 105-113, 2016.

[9] M. Vosough, M. N. Onilghi, and A. Salemi, "Optimization of matrix solid-phase dispersion coupled with high performance liquid chromatography for determination of selected antibiotics in municipal sewage sludge," Analytical Methods, vol. 8, no. 24, pp. 4853-4860, 2016.

[10] E. Patyra, C. Nebot, R. E. Gavilan, A. Cepeda, and K. Kwiatek, "Development and validation of multi-residue and multi-class method for antibacterial substances analysis in non-target feed by liquid, chromatography-tandem mass spectrometry," Food Additives \& Contaminants, vol. 35, no. 3, pp. 467-478, 2018.

[11] W. Jansomboon, S. K. Boontanon, N. Boontanon, C. Polprasert, and C. T. Da, "Monitoring and determination of sulfonamide antibiotics (sulfamethoxydiazine, sulfamethazine, sulfamethoxazole and sulfadiazine) in imported pangasius catfish products in Thailand using liquid chromatography 
coupled with tandem mass spectrometry," Food Chemistry, vol. 212, pp. 635-640, 2016.

[12] H. Xu, X. Chen, L. Guo et al., "Monoclonal antibody-based enzyme-linked immunosorbent assay for detection of total malachite green and crystal violet residues in fishery products," International Journal of Environmental Analytical Chemistry, vol. 93, no. 9, pp. 959-969, 2013.

[13] Y. D. Shen, X. F. Deng, Z. L. Xu et al., "Simultaneous determination of malachite green, brilliant green and crystal violet in grass carp tissues by a broad-specificity indirect competitive enzyme-linked immunosorbent assay," Analytica Chimica Acta, vol. 707, no. 1-2, pp. 148-154, 2011.

[14] Z. Wang, Y. Li, X. Liang, S. Zhang, W. Shi, and J. Shen, "Forcing immunoassay for sulfonamides to higher sensitivity and broader detection spectrum by site heterologous hapten inducing affinity improvement," Analytical Methods, vol. 5, no. 24, pp. 6990-7000, 2013

[15] Y. Tang, J. Gao, X. Liu et al., "Ultrasensitive detection of clenbuterol by a covalent imprinted polymer as a biomimetic antibody," Food Chemistry, vol. 228, no. 1, pp. 62-69, 2017.

[16] J. Xie, B. Zhou, T. Zhang et al., "Preparation of nicotine surface molecularly imprinted polymers for selective solid-phase extraction of nicotine from zero-level refill liquids of electronic cigarettes," Analytical Methods, vol. 10, no. 29, pp. 3637-3644, 2018.

[17] R. Lahsini, M. R. Louhaichi, N. Adhoum, and L. Monser, "Preparation and application of a molecularly imprinted polymer for determination of glibenclamide residues," Acta Pharmaceutica, vol. 63, no. 2, pp. 265-275, 2013.

[18] D. İbrahim, K. Rüstem, O. Ruken, Z. Berrin, E. Arzu, and S. Ridvan, "Molecularly imprinted affinity cryogels for the selective recognition of myoglobin in blood serum," Journal of Molecular Structure, vol. 1174, pp. 171-176, 2018.

[19] H. A. Panahi, A. Feizbakhsh, S. Khaledi, and E. Moniri, "Fabrication of new drug imprinting polymer beads for selective extraction of naproxen in human urine and pharmaceutical samples," International Journal of Pharmaceutics, vol. 441, no. 1-2, pp. 776-780, 2013.

[20] M. Razali, C. Didaskalou, J. F. Kim et al., "Exploring and exploiting the effect of solvent treatment in membrane separations," ACS Applied Materials \& Interfaces, vol. 9, no. 12, pp. 11279-11289, 2017.

[21] R. S. da Silva, M. N. Santos, B. C. Pires et al., "Mesoporous molecularly imprinted polymer for removal of hormones from aqueous medium," Journal of Environmental Chemical Engineering, vol. 590, no. 7, pp. 124506-124512, 2020.

[22] P. Pogány, M. Razali, and G. Szekely, "Experimental and theoretical investigation of the complexation of methacrylic acid and diisopropyl urea," Spectrochimica Acta Part A: Molecular and Biomolecular Spectroscopy, vol. 170, pp. 69-76, 2017.

[23] J. Kupai, M. Razali, S. Buyuktiryaki, R. Kecili, and G. Szekely, "Long-term stability and reusability of molecularly imprinted polymers," Polymer Chemistry, vol. 8, no. 4, pp. 666-673, 2017.

[24] I. Chianella, A. Guerreiro, E. Moczko et al., "Direct replacement of antibodies with molecularly imprinted polymer nanoparticles in ELISA-development of a novel assay for vancomycin," Analytical Chemistry, vol. 85, no. 17, pp. 8462-8468, 2013.

[25] Z. Tang, C. Liu, J. Wang et al., "Preparation and characterization of monodisperse molecularly imprinted polymers for the recognition and enrichment of oleanolic acid," Journal of Separation Science, vol. 39, no. 8, pp. 1592-1602, 2016.

[26] L. Meng, X. Qiao, Z. Xu, J. Xin, and L. Wang, "Development of a direct competitive biomimetic enzyme-linked immunosorbent assay based on a hydrophilic molecularly imprinted membrane for the determination of trichlorfon residues in vegetables," Food Analytical Methods, vol. 5, no. 5, pp. 12291236, 2012.

[27] G. Fang, J. Lu, M. Pan, W. Li, L. Ren, and S. Wang, "Substitution of antibody with molecularly imprinted film in enzyme-linked immunosorbent assay for determination of trace ractopamine in urine and pork samples," Food Analytical Methods, vol. 4, no. 4, pp. 590-597, 2011.

[28] Q. Liu, M. Jiang, Z. Ju, X. Qiao, and Z. Xu, "Development of direct competitive biomimetic immunosorbent assay based on quantum dot label for determination of trichlorfon residues in vegetables," Food Chemistry, vol. 250, no. 1, pp. 134-139, 2018.

[29] P. Weerathunge, R. Ramanathan, R. Shukla, T. K. Sharma, and V. Bansal, "Aptamer-controlled reversible inhibition of gold nanozyme activity for pesticide sensing," Analytical Chemistry, vol. 86, no. 24, pp. 11937-11941, 2014.

[30] L. Han, C. Li, T. Zhang, Q. Lang, and A. Liu, “Au@Ag heterogeneous nanorods as nanozyme interfaces with peroxidase-like activity and their application for one-pot analysis of glucose at nearly neutral $\mathrm{pH}$," ACS Applied Materials \& Interfaces, vol. 7, no. 26, pp. 14463-14470, 2015.

[31] W. Li, B. Chen, H. Zhang et al., "BSA-stabilized Pt nanozyme for peroxidase mimetics and its application on colorimetric detection of mercury(II) ions," Biosensors and Bioelectronics, vol. 66, pp. 251-258, 2015.

[32] S. Oh, J. Kim, V. T. Tran et al., "Magnetic nanozyme-linked immunosorbent assay for ultrasensitive influenza a virus detection," ACS Applied Materials \& Interfaces, vol. 10, no. 15, pp. 12534-12543, 2018.

[33] K. N. Han, J. S. Choi, and J. Kwon, "Gold nanozyme-based paper chip for colorimetric detection of mercury ions," Scientific Reports, vol. 7, no. 1, pp. 2806-2813, 2017.

[34] Y. Zuo, L. Wu, K. Cai et al., "Platinum dendritic-flowers prepared by tellurium nanowires exhibit high electrocatalytic activity for glycerol oxidation," ACS Applied Materials \& Interfaces, vol. 7, no. 32, pp. 17725-17730, 2015.

[35] K. M. Bratlie, H. J. Lee, K. Komvopoulos, P. Yang, and G. A. Somorjai, "Platinum nanoparticle shape effects on benzene hydrogenation selectivity," Nano Letters, vol. 7, no. 10, pp. 3097-3101, 2007.

[36] L. Long, J. Liu, K. Lu et al., "Highly sensitive and robust peroxidase-like activity of au-Pt core/shell nanorod-antigen conjugates for measles virus diagnosis," Journal of Nanobiotechnology, vol. 16, no. 1, pp. 46-56, 2018.

[37] L. Wu, W. Yin, K. Tang et al., "Highly sensitive enzyme-free immunosorbent assay for porcine circovirus type 2 antibody using $\mathrm{Au}-\mathrm{Pt} / \mathrm{SiO}_{2}$ nanocomposites as labels," Biosensors and Bioelectronics, vol. 82, pp. 177-184, 2016.

[38] L. Wang and Y. Yamauchi, "Strategic synthesis of trimetallic Au@Pd@Pt core/shell nanoparticles from poly(vinylpyrrolidone)-based aqueous solution toward highly active electrocatalysts," Chemistry of Materials, vol. 23, no. 9, pp. 2457-2465, 2011.

[39] L. Wu, W. Yin, K. Tang et al., "Enzymatic biosensor of horseradish peroxidase immobilized on Au-Pt nanotube/Au- 
graphene for the simultaneous determination of antioxidants," Analytica Chimica Acta, vol. 933, pp. 89-96, 2016.

[40] L. Liu, B. Du, C. Shang, J. Wang, and E. Wang, "Construction of surface charge-controlled reduced graphene oxide-loaded $\mathrm{Fe}_{3} \mathrm{O}_{4}$ and $\mathrm{Pt}$ nanohybrid for peroxidase mimic with enhanced catalytic activity," Analytica Chimica Acta, vol. 1014, pp. 77$84,2018$.

[41] L. Song, L. Zhang, Y. Huang et al., "Amplifying the signal of localized surface plasmon resonance sensing for the sensitive detection of Escherichia Coli O157:H7," Scientific Reports, vol. 7, no. 1, pp. 3288-3296, 2017.

[42] S. Luo, Y. Liu, H. Rao, Y. Wang, and X. Wang, "Fluorescence and magnetic nanocomposite $\mathrm{Fe}_{3} \mathrm{O}_{4} @ \mathrm{SiO}_{2} @ \mathrm{Au} \mathrm{MNPs}$ as peroxidase mimetics for glucose detection," Analytical Biochemistry, vol. 538, no. 1, pp. 26-33, 2017.

[43] W. He, Y. Liu, J. Yuan et al., “Au@pt nanostructures as oxidase and peroxidase mimetics for use in immunoassays," Biomaterials, vol. 32, no. 4, pp. 1139-1147, 2011. 